\title{
Itinerários vegetais, ou da inconstância da aldeia banawá
}

Miguel Aparicio ${ }^{1}$

\section{Resumo}

As transformações vividas pelos Banawá (Arawá, Purus) nas últimas décadas remetem a um movimento em que as figuras de alteridade, sejam elas vegetais ou humanas, produzem uma oscilação constante entre a itinerância e a estabilidade. Incapazes de serem confinados na condição de "nômades" ou de "sedentários", os Banawá desenvolvem práticas que também não se circunscrevem ao que convencionalmente se conhece como "caça e coleta", por um lado, ou "agricultura", por outro. Um olhar atento sobre a mitologia e sobre as relações com a floresta revelam que os processos de "perda da agricultura", ou de retomada, alternância ou incorporação, se constituem como escolhas políticas. Nesse sentido, aldeia, roça e floresta não expressam tanto geografias da permanência ou da mudança, mas topologias inspiradas na inconstância da vida coletiva.

Palavras-chave: Banawá; Purus; Agricultura Indígena; Caçadores-Coletores; Relações Humanos-Plantas.

\begin{abstract}
The transformations experienced by the Banawá (Arawá, Purus) in the last decades refer to a movement in which the figures of otherness, whether vegetable or human, produce a constant oscillation between itinerancy and stability. Unable to reduce themselves to the condition of "nomad" or "sedentary", the Banawá develop practices that are also not limited to what is conventionally known as "hunting and gathering", on the one hand, or "agriculture", on the other. A close look at mythology and relations with the forest reveals that the processes of "loss of agriculture", or of resumption, alternation or incorporation, constitute political choices. In this sense, village, gardens and forest do not express so much a geography of permanence or change, but topologies inspired by the inconstancy of collective life.
\end{abstract}

Keywords: Banawa; Purus. Indigenous Agriculture; Hunters and gatherers; Human-Plants Relations.

1 Professor Adjunto no Programa de Antropologia e Arqueologia da Universidade Federal do Oeste do Pará e Doutor em Antropologia Social pela Universidade Federal do Rio de Janeiro. E-mail: mgl.aparicio@gmail.com. 
Conhecidos até meados do século XX como Jamamadi do Apituã, os Banawá são um grupo falante da língua madi (Arawá), a qual compartilham com os Jamamadi orientais, os Jarawara e os isolados Hi Merimã. Procedentes de regiões próximas às várzeas do rio Purus, no Amazonas, após conflitos intensos com seringalistas, se deslocaram a regiões interfluviais, aproximando-se do rio Piranhas, um subafluente do Purus na sua margem ocidental ${ }^{2}$. Um mito banawá sobre o surgimento dos grandes rios, entre os quais o Purus, vincula esse evento com o aparecimento dos Paumari, dos $\mathrm{yara}^{3}$, de suas máquinas e mercadorias assim como de seus cultivares. Na narrativa, que assume um ponto de vista "da terra-firme", a trama foca nas transformações ocorridas nos ambientes de várzea, e manifesta a curiosidade e inquietação despertada pela irrupção de barcos e navios nas águas do Waforofai, "o Rio dos Vapores”. Os habitantes da várzea (os animais $b_{a n i}{ }^{4}$, os Paumari e os yara) são o fio condutor da transformação do mito, que na sombra de um segundo plano faz também referência aos novos cultivares. A partir dessa presença marginal das plantas cultivadas na mitologia, e de uma intrigante "negação da agricultura" recorrente em seus discursos cotidianos, os Banawá despertaram em mim questões que insinuavam uma distância acentuada em relação a alguns conceitos da ecologia amazônica: sua memória sobre os lugares, suas ideias sobre as plantas e suas práticas de habitação, cultivo e mobilidade desestabilizavam certas convenções em torno ao significado de categorias como "aldeia", "cultivar", "agricultura", ou da condição de "caçadores-coletores", apontando divergências desafiadoras.

Antigamente não havia rios, somente a mata (yama kabani). Havia quatro irmãos: um deles ficou doente e começou a sangrar continuamente pelo ânus. As pessoas queriam mudar de lugar, mas ele preferia ficar sozinho. A sua irmã chegou com carne para ele comer, mas ele não quis. A irmã dele pediu: "Venha conosco". "Não, eu não vou", respondeu. Ela insistiu, mas ele disse: "Eu não vou, mas você pode trazer comida para mim. Traga bolo para eu comer". "O que é bolo?", disse a irmã - ela não sabia o que era bolo, e levou ao homem que sangrava beijus e tapiocas para se alimentar. Seu irmão chegou e disse: "Venha conosco, eu vou lhe levar". Mas ele respondeu: "Não, eu não vou. Vou ficar aqui, vai ser ruim vocês cuidarem de mim. Podem ir". As pessoas se mudaram. Do sangue que saia do ânus dele se formou um igarapé, que foi descendo,

2 A população banawá atual é de aproximadamente 130 pessoas, distribuídas nas localidades Maloca (um antigo aldeamento promovido pelos missionários do SIL a partir de diversos grupos itinerantes), Paraíba ("colocação" extrativista onde se instalaram alguns Banawá a partir do estreitamento de relações com patrões regionais) e outros locais residenciais menores disseminados no seu território. Nesses locais continuam circulando as pessoas das atuais “aldeias” Maloca e Paraíba. Note-se que a onomástica aldeã já expressa de forma eloquente a tensão vivida pelos Banawá nos seus itinerários, como veremos nas páginas a seguir.

3 Os yara, para a maioria dos grupos arawá, são os não indígenas, os “brancos”, donos das mercadorias, barcos e máquinas.

4 Bani faz referência aos animais na posição de "presas". Versões alternativas do mito que apresento a seguir fazem ênfase no aparecimento das ciganas wakari, jacamins kosefo e diversos animais de várzea no processo de transformações.

5 Minha relação com os Banawá iniciou em 1993 no seringal Santo Antônio do Apituã e na cidade de Canutama, e continuou esporadicamente durante anos. Porém, meu trabalho de campo intensivo teve lugar a partir de 2014, durante a pesquisa etnográfica de meu doutorado em Antropologia Social no Museu Nacional. 
atravessando a mata. Naquele tempo não havia igarapés, era tudo terra-firme.

No dia seguinte o irmão mais novo saiu de manhã cedo do lugar onde todos estavam, ele disse: "Vou buscar o nosso irmão e vou trazê-lo". Chegou ao local onde seu irmão estava e insistiu para que voltasse com todos. Conversou com ele, que estava deitado na rede. Conversaram o dia inteiro, ele disse assim: "Eu não vou, eu vou ficar aqui. Amanhã vocês vão ver o que vai acontecer. Vocês vão trabalhar muito para mim, vão trabalhar com sorva, copaíba, castanha, fantasia ${ }^{6}$. Vocês vão suar muito, muito mesmo. Amanhã, antes do amanhecer, vocês escutarão um estrondo, um barulho forte, então vocês vão saber o que vai acontecer". O irmão mais novo voltou sozinho e contou aos seus a conversa que tinha tido com seu irmão que sangrava. Dormiram, e antes do amanhecer acordou todo mundo e disse: "Pai, o nosso irmão diz que vai haver um barulho muito forte antes do amanhecer".

E assim ocorreu, de fato. Ouviram um estrondo e foram ver o que tinha acontecido. Havia barulho de navios, de barcos a vapor ${ }^{7}$. Ao chegar viram uma capoeira e, no local onde ele permanecia, um rio, um rio grande de água barrenta que vinha da mata acima e que seguia para baixo, arrastando muitos troncos. Cortaram muitas árvores para fazer uma jangada e descer o rio à procura do irmão. $\mathrm{O}$ irmão deles tinha se transformado em rio.

Eles se perguntaram: "Onde será que nosso irmão está? Para cima ou para baixo?" "Acho que está para baixo", disse alguém. Então desceram o rio na jangada que eles tinham feito e se transformaram nos Paumari ${ }^{8}$. No rio navegavam muitos barcos e navios, e à beira havia panelas, tambores, garrafas, espingardas. Na beira do rio apareceram as casas, as panelas, as espingardas, as mercadorias, os barcos, tudo. Havia muitas latas - latas grandes, como era antigamente: de pólvora, de chumbo, de manteiga, de bolachas, de açúcar, de café. Viram às margens do rio casas velhas de yara, com latas e motores, todos velhos. Não morava ninguém nessas casas. Continuaram descendo e viram mais e mais casas, para baixo as casas eram maiores e mais bonitas. Nessas casas moravam os yara, e havia muitas mercadorias. Seu irmão tinha se transformado em todas aquelas coisas. À beira havia também muitas bananeiras, mandioca, macaxeira e todos os cultivares (yama korona) nos quais seu irmão tinha se transformado.

6 A expressão "fantasia" faz referência às peles de luxo abatidas por caçadores para o mercado regional, de maneira específica, as da onça-pintada (Panthera onca), do maracajá-açu (Leopardus pardalis), do maracajá-peludo (Leopardus wiedii), da ariranha (Pteronura brasiliensis) e da lontra (Lontra longicaudis) (ANTUNES, 2017: 20).

$7 \quad$ Narrativas suruwaha também dão destaque ao trânsito intenso de barcos a vapor na época do auge extrativista: "Na terra dos yara havia uma casa que ficava debaixo d'água, a sua cumeeira sobressaía por cima das águas do rio; dela emanava uma fumaça procedente das fogueiras da casa. Naquela casa moravam pessoas debaixo d'água, faziam fogo e criavam cães, cães muito bonitos e bem cuidados. Havia muitos objetos de diferentes tamanhos, usados para guardar pertences; eram semelhantes a ninhos de vespa, como sacolas de plástico que os yara usavam. Para entrar na casa que estava debaixo das águas, as pessoas remavam pelo rio e penetravam no fundo. Escutava-se um barulho parecido ao do avião, era o barulho daquela casa dos yara que andava no rio" (Uhuzai, 1999, casa de Hinijai, Suruwaha,).

8 Os Paumari são denominados pelos Banawá com o nome da cigana, wakari (Opisthocomus hoazin), ave que habita em ambientes de várzea. 
Continuaram a viagem perguntando às pessoas: "Vocês viram nosso irmão?" "Ele já passou por aqui, ele desceu, está na cidade", disseram. "Nós vamos atrás dele", responderam. Desceram mais e chegaram a uma cidade enorme, onde havia uma multidão de yara. A cidade estava cheia de mercadorias. Passaram três dias andando pela cidade, até que encontraram uma feira muito grande, cheia de produtos. Seu irmão estava no centro do mercado, anotando no livro e pegando a produção das pessoas que trabalhavam para ele. O irmão dele tinha virado patrão. Eles se aproximaram e abraçaram seu irmão. Todos ficaram muito alegres. Ele disse: "Sofri muito, mas agora estou com saúde. Eu quero que agora vocês trabalhem para mim. Vocês vão tirar madeira, sorva e copaíba e vão ganhar muita mercadoria". E assim conseguiram açúcar, bolacha, sabão, panelas, motores, espingardas, todas as mercadorias. Os irmãos dele voltaram com as coisas, voltaram com a mercadoria que o irmão tinha dado a eles. Fizeram flutuantes e foram morar à beira do rio (Badi, 2016, Maloca).

Lévi-Strauss já tinha reconhecido na mitologia sul-americana associações entre a algazarra, o sangue menstrual e os excrementos ([1967] 2004: 329). O mito apresenta uma série de transformações em que uma hemorragia anal masculina se torna geradora de pessoas e artefatos novos, após produzir um estrondo no instante do seu surgimento: trata-se de uma espécie de antimenstruação em que o sangue (aqui, masculino) perde seu caráter de "sujeira e veneno" (Op. Cit.: 193) e produz um efeito fecundo de produção de pessoas (estrangeiras). A conexão/ inversão em relação aos habituais ritos de clausura das jovens na menarca é patente: o homem mantém uma dieta alimentar adequada - não aceita carne, consome beijus e tapiocas (mas deseja bolos, alimento não cruento próprio dos estrangeiros que irá gerar) - e se separa dos parentes, negando-se a conviver na casa dos irmãos. A sua hemorragia/excremento, causa de um estado de antiparentesco, manifesta um "efeito vital do tóxico" (RODGERS, 2002) através de um sangue gerador de não parentes.

Como é comum em diversas concepções amazônicas, "o sangue é uma espécie de móvel da transformação, da possibilidade de dar surgimento a outros seres" (GONÇALVES, 2001: 233). Estas transformações agem em diversos níveis: o sangue dá origem ao rio; ao estrondo inicial sucede o barulho dos barcos a vapor; o homem doente se transforma em yara por excelência, na sua condição de patrão; as pessoas se transformam em Paumari, que irão trabalhar como seus empregados; e o movimento de descida passa de um cenário de casas velhas desabitadas primeiro a casas novas e bonitas com abundância de mercadorias mais adiante, até o cúmulo da afluência que é possível encontrar na grande cidade. O sangue age efetivamente como "operador de perspectivas" (BELAUNDE, 2006: 232).

O mito confirma ainda a descrição banawá de um mundo em que as plantas cultivadas são adquiridas a partir do estreitamento das relações com os yara: elas são mais um elemento entre as inovações que emergem no fluxo de transformação. No processo de obtenção de ferramentas, espingardas, mercadorias, cultivares, a apropriação da diferença é extrapolada ao ponto de provocar uma transformação dos parentes (os irmãos do novo patrão) em Paumari. Uma temática 
recorrente em outras mitologias: os bens dos yara precisam ser conquistados ou pagos ao preço deles próprios se tornarem estrangeiros (LAGROU, 2006: 70).

O comparecimento de plantas como a mandioca ou a macaxeira faz parte de um processo de devir-yara que ocorre no mundo das várzeas: o "Rio dos Vapores" está repleto de roças abundantes ao longo de seus seringais nas praias férteis: um ambiente diverso daquele a partir do qual os Banawá pensam a sua própria origem arbórea: “As pessoas procedem do buraco da árvore do pequiá. Um temporal forte derrubou a árvore que, ao cair, partiu o tronco no meio: dele saíram as pessoas. As pessoas que saíram do pequiá foram morar na foz do igarapé Waa, no Wamoriá. Depois as pessoas aumentaram e se espalharam" (Toefi, 2015, Maloca).

A procedência das pessoas antigas (ee bote) do buraco da árvore de pequiá caída conecta os Banawá com mitologias análogas entre outros grupos Arawá. Um mito suruwaha, por exemplo (APARICIO, 2015), adere a esta origem vegetal/arbórea dos humanos: Ajimarihi (o "avô-onçca" que possui uma posição de demiurgo) caminhava pela mata à procura de frutas, a partir das quais foram surgindo os diversos povos. Pegava as frutas, as esfregava, soprava nelas e pedia que falassem, mas as falas das pessoas que surgiam eram feias (ati tijuwanaxu) e confusas (danuzyri). Dessa maneira, os Juma surgiram da fruta de ucuqui, por isso eles são altos e grandes. Da semente de patauá surgiram os Zamadi, cuja fala é incompreensível. E da fruta da árvore do breu surgiram os Sanamadi, predecessores dos Suruwaha: ao esfregar as frutas do breu, Ajimarihi viu que elas se transformavam em pessoas de fala agradável, com a pele bonita, pintada de urucum. Surgiram dois casais, futuros maridos e futuras esposas: os homens aprenderam de Ajimarihi a maneira de construir a casa, de levantar os esteios e de tecer a cobertura de caranaí, assim como a elaboração das flechas e o preparo do curare e do tabaco. Da esposa dele, Jumanihia, as mulheres aprenderam a tecer redes, fiar algodão e trabalhar com a argila para fabricar panelas e alguidares.

Uma narrativa jarawara conta o extermínio do povo após o ataque dos inimigos canibais Juma. Apenas uma mulher sobrevive, permanecendo escondida no buraco de uma árvore, protegida com uma flecha besuntada com sangue menstrual. Após o encontro com um caçador na floresta, ela tece duas redes de algodão com seu fuso, prepara massa de mandioca iyawa e casa com ele: o casal tem muitos filhos, e o povo cresce novamente (SCHRÖDER E MAIZZA, 2018). Na mitologia kulina, Tamako e Kira, irmãos primordiais, promovem transformações de árvores em animais, gerando os diversos grupos de gente (ALTMANN, 1995: 166-171). Kira fez surgir os animais a partir de pedaços de âmago de árvores, assim como os brancos. Seu irmão Tamako faz surgir os madiha a partir das palmeiras (jaci, ouricuri, babaçu... $)^{9}$.

Em um sentido análogo, os Jamamadi orientais identificam diversos coletivos que convergiram na sua formação contemporânea. Segundo Kere ${ }^{10}$, estes "subgrupos" são os Wayafi, Hawa,

9 Em relação aos coletivos madiha, Amorim (2016: 114), com pesquisa na Terra Indígena Lago Ualá, no baixo Juruá, identifica treze denominações, entre as quais nara madiha (referente à palmeira-jaci), dsawida madiha (pupunha) e hawa madiha (patauá).

10 Comunicação de Kere, jamamadi, durante o encontro "Diálogos sobre isolamento e contato: Os Hi Merimã e os povos do seu entorno", promovido pelo Centro de Trabalho Indigenista e a Funai na Base da Frente de Proteção

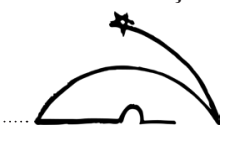




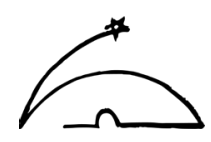

Kosiba (que ele identifica como "Jamamadi de verdade"), Hi Merimã, Banawá, Boti, Nakanike madi (os "Kanamadi” do igarapé Sabuhun), Awabodi yafi e Wadi: várias destas denominações correspondem a nomes de palmeiras ${ }^{11}$, apontando assim uma origem arbórea dos humanos: perguntar a um Jamamadi a qual grupo ele pertence seria, em realidade, perguntar "de qual árvore você provém" (SHIRATORI, 2018: 336).

A reconstrução das trajetórias nativas mostra a pista das transformações topológicas que balizam a memória coletiva. Há uma qualidade constitutiva na relação entre os humanos e os lugares que eles habitam, e que fundamenta o regime banawá de territorialidade: "lugares emergem nos discursos indígenas como coisas que oscilam entre um evento e um sujeito - um agente ou uma congregação mais ou menos temporária, mais ou menos 'harmônica' de uma pluralidade de agentes" (COELHO DE SOUZA, 2017: 12). Trata-se de uma história que consiste na construção de novas localidades, de um processo permanente de fabricação de lugares humanizados por parentes. E nesse marco os novos cultivares fazem sentido para as "pessoas verdadeiras" (ee yokana): as plantas cultivadas fazem parte de lugares habitados, em contraste com o mundo anônimo da floresta. Neste sentido, é pertinente afirmar que yama korona (os cultivares) são as plantas engajadas com os humanos e seus lugares, em contraste com yama kabani - a mata como espaço de indistinção.

\section{Plantas cultivadas "reagregando o social"}

As narrativas que circulam entre os Banawá apontam uma trajetória que oscila em dois movimentos: um movimento de "guerra" em torno às experiências de violência nas relações com o extrativismo seringueiro da várzea do Purus (a leste da atual terra demarcada); e um movimento de "pacificação" nas relações com o extrativismo sorveiro e castanheiro das terras firmes do interflúvio Purus-Piranhas (a oeste da atual terra demarcada) ${ }^{12}$. As relações com essas duas frentes coloniais não foram homogêneas: é preciso reconhecer contrastes no engajamento vivido pelos Banawá nesses circuitos relacionais. De alguma maneira, me parece oportuno afirmar que o extrativismo seringalista da várzea do Purus, onde havia uma maior concentração de seringueiras (Hevea brasiliensis), é um extrativismo mais institucionalizado, com uma organização sólida, "molar”, no qual confluíam os interesses das grandes empresas internacionais com os das elites políticas e comerciais do Amazonas nas cidades interioranas. Em contraste, havia nos hinterlands do rio Piranhas (e dos rios Tapauá e Cuniuá, principais rotas fluviais nessa região do grande interflúvio

Hi Merimã no rio Piranhas, com participação de indígenas Banawá e Jamamadi, em novembro de 2016.

11 Assim, hawa corresponde ao patauá; kosiba, ao ouricuri; boti, à palmeira inajá.

12 Para uma cronologia desta dinâmica, indiquemos que a crise nas relações dos Banawá com o seringalismo do Purus eclodiu nos anos 1930, a partir de episódios violentos em torno ao centro seringalista de Santo Antônio do Apituã, no Purus. O envolvimento dos Banawá com o extrativismo sorveiro do rio Piranhas se intensificou a partir de finais da década de 1950, e continuou até os anos 1980 (informações mais detalhadas em APARICIO, 2019). 
Purus-Juruá) um extrativismo alternativo, menos centralizado, "molecular" e com maior transitoriedade em função dos produtos em torno aos quais ele se organizava: o látex da sorva (Couma utilis), "espacialmente instável” e a castanha (Bertholletia excelsa), "temporalmente instável”. A coleta de látex de seringa podia ser programada e organizada de forma estável, pois as estradas de seringa eram circuitos permanentes que partiam das colocações (ALMEIDA, 2012), o que não ocorria, por exemplo, com a extração de látex de sorva - identificar sorveiras na floresta é uma atividade que exige amplos deslocamentos, e que não possui a rotina cotidiana da estrada de seringa. Seringalistas e seringueiros, ao consolidar uma ocupação permanente e completa das áreas de várzea, promoveram uma ocupação mais agressiva, violenta, que forçou os Banawá a estabelecer-se em áreas de terra-firme mais distantes do Waforofai, do "Rio dos Vapores".

Nesse novo contexto de retaguarda comercial dos circuitos extrativistas, podemos estender aos Banawá a mesma afirmação que Peter Gow fez em relação aos Piro: eles introduziam os patrões do extrativismo na sua rede de trocas (2006: 451). Após a experiência falida e violenta nos movimentos de aproximação aos patrões da várzea do Purus, uma nova manobra dos Banawá aponta ao estabelecimento de relações com os sorveiros e castanheiros do rio Piranhas e com seus patrões. Traça-se assim uma dinâmica análoga à que Dal Poz, adotando a expressão do jornalista Mário Chimanovitch ${ }^{13}$, identificou entre os Cinta Larga como pacificação dos brancos (DAL POZ, 1991: 73), categoria consolidada de modo definitivo na etnologia amazonista a partir da coletânea de Albert e Ramos: colocam-se em foco "dispositivos não apenas de representação, mas de domesticação simbólica e ritual da alteridade dos brancos e de neutralização dos seus poderes nefastos (pestilência e violência)" (2000: 10). Esta perspectiva de pacificação às avessas se constitui efetivamente em um processo de "domesticação dos brancos" (KELLY, 2005).

Em meados dos anos 1950, portanto, os Banawá exploram com maior frequência dois igarapés que eles conheciam como Kitiya (afluente do Piranhas que os extrativistas denominam igarapé Banawá) e um pequeno tributário seu, o Yatifa ("igarapé das pedras"). Na região percebem a intensa movimentação de sorveiros e castanheiros que tinham o rio Piranhas como eixo principal. Nesse cenário os líderes Sawa e Tofe, avessos ao estabelecimento de hostilidades após a experiência vivida na região do Apituã, promovem uma relação cordial com o principal patrão atuante no rio Piranhas: o maranhense Firmino Cunha. Este "amansamento" dos yara atualiza a capacidade de "inovação audaciosa" que Lévi-Strauss ([1942]1976) identifica como potência

13 "Pela primeira vez em toda a história do indigenismo brasileiro, um povo absolutamente primitivo entrou em contato, por sua própria iniciativa, com uma comunidade de cientistas e tecnólogos instalada em plena selva amazônica. Sábado e domingo últimos, três guerreiros de um numeroso grupo 'Cinta-Larga' até hoje não contatado por qualquer civilizado, acompanhado de suas mulheres e filhos, irromperam na Cidade-Laboratório de Humboldt localizada a cerca de mil quilômetros de Cuiabá, no Norte de Mato Grosso. A entrada dos 'Cintas-Largas' naquele centro de pesquisas avançadas é para os cientistas de Humboldt nada menos que a culminância de um processo de 'pacificação' iniciado pelos próprios índios em outubro do ano passado, quando deixaram belíssimos presentes para uma equipe de Botânica do Instituto Nacional de Pesquisas da Amazônia que realizava estudos na área. A partir daí, surpreendentemente, foram os índios quem conduziram integramente o 'namoro' com os brancos que, por sua vez, limitaram-se pacientemente a aguardar a iniciativa de um contato" (Chimanovitch, 1974). Diversas etnografias descreverão as relações dos indígenas com os brancos em termos de pacificação. 


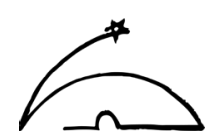

transformacional nas estruturas tradicionais, e o movimento reverso que pode ser projetado sobre os que detêm a posição (instável) de domínio.

Os Banawá se movimentam ao longo do interflúvio Purus-Piranhas estabelecendo-se em um conjunto de localidades conectadas por uma profusa rede de caminhos, e mantendo uma intensa mobilidade através das campinaranas e florestas altas da região. Os relatos entrecruzados sobre a circulação coletiva entre o Purus e o Piranhas revelam uma dinâmica de relações que oscila constantemente entre um movimento de caráter autônomo e uma orientação reticular: pequenos coletivos estabelecem seus lugares de residência, em intercâmbio e proximidade com outros, em uma convivência que torna simultânea a independência relativa e a participação em uma rede de relações. Não existe sociedade, não existem subgrupos constituintes de uma unidade maior: os pequenos coletivos Banawá se recompõem continuamente e criam lugares habitáveis em uma constelação de vizinhanças, em encruzilhadas que comunicam uns acampamentos com outros. Mais do que "autonomia" entre os pequenos coletivos, o que os define é o fato de viverem entre si - o cotidiano os diferencia, mas suas diferenças se recriam cotidianamente. Poderia ser aplicada a eles a descrição que Clastres desenvolve sobre os Aché, sem acreditarmos muito na consistência dos "limites":

Os bandos de uma mesma tribo mantinham relações forçosamente amigáveis, pois que se compunham não somente [...] de companheiros, mas de parentes. De vez em quando, dois bandos podiam encontrar-se, acampavam alguns dias juntos, para partir em seguida cada um para seu lado. Mas, a princípio, cada grupo nomadiza só, nos limites do seu próprio espaço vital [...], levando uma vida em tudo semelhante à dos vizinhos" (CLASTRES [1972] 1995: 167).

Ao mesmo tempo, vai sendo gestada uma transformação, e as pessoas que transitaram nas florestas e campinaranas entre os dois rios maiores indicam que ela surgiu a partir de uma relação: a relação com as plantas cultivadas, yama korona. Com elas parece reforçar-se a tensão unificante que deu origem a um lugar muito lembrado por todos: Tabora Made, a "Maloca Grande".

Tabora Made foi a principal localidade dos Banawá no seu movimento de aproximação ao rio Piranhas e ao "extrativismo pacificado" nas relações com o patrão sorveiro e castanheiro Firmino Cunha. Nessa época era o maior assentamento residencial, mas as pessoas mantinham a diversidade de lugares, com famílias residindo em Latawadi, Iakaomi e nos igarapés Mayofa e Yatifa, além de outras pequenas localidades. Alguns estabeleceram sazonalmente novas residências em afluentes do Piranhas, mais perto da presença extrativista. A consolidação de Tabora Made foi estratégica: próximo à beira do Piranhas, mas ainda a algumas horas de distância na terra-firme, era um autêntico cruzamento de caminhos conectados com os principais lugares residenciais. Com efeito, a rede de caminhos enlaçava a "Maloca Grande" com uma constelação de lugares habitados, que incluía também o barracão do Palhalzinho, moradia do patrão Firmino. Tabora Made se firma como um ponto de conexões privilegiadas. Inácio faz a seguinte síntese deste itinerário, 
marcando os sucessivos lugares que marcaram a vida coletiva dos Banawá:

No tempo de Sawa e Karara, as pessoas não plantavam roça, não tinham mandioca nem macaxeira. Comiam castanha, comiam cará-do-ar, comiam babaçu e patauá. Guardavam as frutas de buriti na beira dos igarapés, dentro d'água, onde permanecia durante um tempo. Roubaram plantas dos yara e fizeram a primeira roça no igarapé Quaru. Em Santo Antônio do Apituã estava o patrão Janjão Pontes. Foi o tempo em que um tal Firera começou a fazer marretagem. Doo era um dos que começou a fazer trocas com Firera. Algumas pessoas moravam na cabeceira do Apituã, no Bacia. Firera teve relação com a irmã de Hokoro, que não gostava disso. Um dia, mexendo com uma espingarda (daquelas que são carregadas introduzindo a pólvora pelo cano), Hokoro matou Firera. As pessoas voltaram com muita mercadoria, Doo e os outros. Sawa estranhou isso e suspeitou que alguma coisa tinha acontecido. Quando descobriu a morte de Firera, Sawa brigou com Hokoro e tomou sua arma.

Por causa das brigas, as pessoas mudaram a Bokoyafi e depois a Latawadi. Latawadi era o local onde tinham achado latas dos yara. Nessa época Manoelzinho, um jamamadi que trabalhava com Firmino, se aproximou das pessoas e conseguiu que elas se envolvessem no comércio com o patrão. Moraram por um tempo no Mitomefai. Depois foi a época da Maloca Grande do Yatifa, Tabora Made. Bibi foi morar no igarapé Beyefa. Dedé e Nenê foram fazer roça dentro do igarapé Banawá. Outras pessoas moravam no local do atual campo de pouso. Eu e minha mãe viemos morar no Raul Guedes, mais perto do rio Piranhas. Mas houve brigas e ciúmes dos ribeirinhos pois Sérgio e eu éramos jovens e flertávamos com as moças da região. Depois de diversos locais, viemos morar na Paraíba, no igarapé Banawá (Inácio, 2015, Paraíba).

A presença marcante dos cultivares na vida cotidiana é mais uma das novidades que derivam da aproximação ao convívio com os yara: roubados em um primeiro momento das roças dos seringueiros na região do Purus, e obtidos nas trocas com os sorveiros habitantes do Piranhas em um segundo momento. Os Banawá, nos primeiros anos da relação com o patrão Firmino, eram chamados para realizar a derrubada e plantio dos roçados yara, sendo eles a principal mão-de-obra na produção de farinha de mandioca para a frente extrativista: a farinha ensacada garantia estoques suficientes para dar suporte alimentar nas atividades extrativistas distantes dos núcleos residenciais - extração de sorva e copaíba, caça de animais para comercialização de peles, coleta nos castanhais. Dessa forma, eles foram também inserindo pequenas roças de mandioca nas suas localidades. Chama atenção a insistência deles no caráter inovador destas práticas, com um discurso que afirma um momento precedente de "caça e coleta" e de "ausência de agricultura". Toefi afirma hoje que as pessoas não tinham roçado, comiam castanha, babaçu, buriti, patauá, castanha-de-cutia, louro-abacate e cará-do-ar (yarabia) 14. “As pessoas roubavam milho, cará e

14 É interessante o nome desta dioscoreácea na língua Banawá: yarabia significa "batata de branco". Chama a atenção a importância e diversidade de tubérculos na dieta banawá passada e contemporânea: além do yarabia (que cresce nos quintais e capoeiras), eles identificam também: yamabia (abundante na região do igarapé Faerebo, é con-

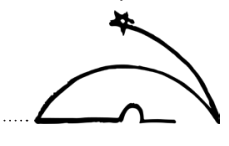




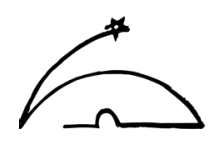

abacaxi no Purus, e levavam essas plantas às suas casas; depois de um tempo levaram também manivas ${ }^{15}$. Comiam ayawa ${ }^{16}$, não produziam farinha", explica Toefi.

Outras espécies que destacam nos relatos sobre a dieta dos antigos são a pupunha, o tucumã, o ouricuri, o uxi, o pequiá, a balata, a partir dos quais elaboravam massas raladas cruas, mingaus fermentados (é o caso da pupunha) ou grolados ayawa, como continua sendo habitual em algumas casas da Maloca. Observa-se uma predileção arboricultora presente na trajetória banawá. A jovem Ildete, que reside na cidade de Lábrea, fez a seguinte descrição sobre a antiga vida de seus parentes:

Os Banawá eram um grupo grande que se dividia. Habitavam em casas pequenas de jarina e caranaí, com um terreiro para reunir-se e cheirar rapé. Se alimentavam de caça e peixe (jiju, traíra, matrinxã), ayawa de babaçu e massa de patauá. Usavam farinha de babaçu e farinha de uxi; a farinha de mandioca chegou depois. As plantas preferidas eram uxi, buriti, balata, ouricuri, pupunha, tucumã. Sopravam e faziam aspersão com água antes de coletar a planta, como respeito ao espírito da planta. Celebravam o ritual da menina moça. Sentavam em toras para cheirar rapé. Reconheciam o feitiço arabani nas estrelas cadentes que os Jamamadi enviavam. Protegiam-se com rapé do feitiço das estrelas. Os donos das plantas não permitiam que ninguém mexesse com elas; se alguém o fizesse, o dono descascava, derrubava e matava as plantas. Cada pessoa tinha o seu caminho, o dono do caminho era o dono das plantas (Ildete, 2015, Lábrea).

A "ausência de agricultura" como qualificação da vida antiga é concomitante a um outro elemento a destacar: a negação da "aldeia" nos tempos de itinerância nas florestas e campinaranas interfluviais. A organização do espaço habitacional de forma estável, como aglomerado de casas ao redor de um terreiro, é avaliada também pelos Banawá como uma espécie de inovação contemporânea, que tem Tabora Made como primeira iniciativa e que prosseguiu, até hoje, com as configurações residenciais da Maloca e da Paraíba. De fato, não existe um conceito equivalente ao de "aldeia" na língua Banawá - os termos mais próximos, tabora e yobe podem ser traduzidos respectivamente como "lar" e como "casa", não propriamente como "aldeia" ". A conexão entre

sumida habitualmente pelos queixadas; se cozinhada, pode ser comida pelas pessoas, mas atualmente a maioria dos Banawá tem receio dela); hosi (batata-doce, com as variedades hosi ama e hosi sawa, respectivamente batata-doce vermelha e branca ); hoso (também denominada yobo); ki (presente em roças e quintais); wafe (ariá); e as variedades de bia, os carás: bia mase mawakana, bia noki soki, bia noki sawa (respectivamente, carás vermelho, preto e branco).

15 Em relação às mandiocas, os Banawá identificam as variedades fowa mara, koyo, fowa nere, fowa kabei nere, hoha yisero, fowa kabei (macaxeira) e outras com denominações em português: janoacá, mandioca-amarela, mandioca-branca, flecheira, ligeira, baxata e cobiçada.

16 A massa de mandioca fresca ralada, espremida no tipiti e esquentada depois no alguidar, finalmente consumida em forma de grolado.

17 O termo yobe expressa fundamentalmente a casa no seu aspecto material. As habitações yobe dos Banawá consistiam em uma construção simples, de dimensões reduzidas, de chão batido, com cobertura e paredes de palmas de babaçu e jarina. Com o contato extrativista, adotaram a casa elevada sobre o chão, com assoalho de ripas de paxiúba e cobertura de caranaí. Há uma tendência recente a adotar a casa com assoalho e paredes elaboradas com 
aldeia e roçado (fadara) parece constituir um traço dos tempos novos.

Esse acoplamento singular entre a casa $u d a$ e o roçado hadara é significativo também entre os Suruwaha. Com efeito, para eles o roçado não está na casa, ao lado dela: ao contrário, é a casa que está situada na roça. Assim como para os Wajãpi na região das Guianas, para os Suruwaha e os Banawá "toda aldeia nasce dentro de uma roça - um lugar previamente socializado e amansado" (CABRAL DE OLIVEIRA, 2016: 117). É a presença dos cultivares na roça que deriva na instalação da casa - parece que as plantas agem "reagregando o social"18. Os Banawá desenvolvem a respeito uma reflexão interessante sobre o par roça/aldeia. Inácio é veemente ao afirmar o contraste entre o nomadismo do "índio brabo" e a estabilidade aldeã do "índio civilizado". No depoimento a seguir, ele descreve a maneira de ser dos "índios-de-rabo"19 e dos Suruwaha:

Esse índio acho que, para ter aldeia mesmo, só se tivesse contato. Tiro exemplo dos Suruwaha. Os Suruwaha conhecem tudo por aqui pelo Piranhas, para cima. Saíram no Bernaldo, andavam por aí todo, pelo rio Branco. Agora, depois que pegaram fogo, arranjaram uma planta. O índio não tem planta, a comida do índio, a farinha dele, é babaçu e o que chamam pão-de-índio, porque eles comem, mas não é o pão que ele planta: é orelha-de-pau que se transforma. Eu conheço muito bem: chamam pão-de-índio porque eles comem, não tem outro. Comem todo tipo de fruta, até nós mesmos já comíamos também. A farinha hoje em dia que a gente vê comentar, o pessoal que trabalha na Funai que vai para lá... Têm abacaxi, os Suruwaha têm cará, têm banana, mas não é através da cultura deles, mas que ele traz dos brancos. Sei muito bem que essas frutas que eles têm foram carregadas do patrão Manoel Sena, o pessoal já contou. Depois que eles têm aquelas plantas, ai que têm aldeia - assim como nós, tiro por nós também [grifo meu] (Inácio, 2016, Foz do Aripuanã).

Ou seja, a formação da aldeia decorre da instalação dos cultivares na roça. Os "índios-de-rabo" persistem, neste sentido, em uma forma de vida que corresponde, no discurso de Inácio, à vida que os Suruwaha, os Banawá e os Jamamadi tinham no passado.

tábuas de madeiras de lei, com telhado de alumínio. Os Banawá contratam vizinhos ribeirinhos ou jamamadi para serrar as madeiras e para o próprio processo de construção da casa. Na Maloca há ainda algumas yobe bidi ("casas pequenas" ao estilo antigo) usadas pelas mulheres idosas durante o dia. Estas casas estão ao lado das casas maiores de seus filhos e filhas (onde elas pernoitam), mas garantem independência e tranquilidade a elas. Nas yobe bidi as idosas preparam a comida, descansam nas suas redes e conversam com as demais mulheres ao longo da jornada.

18 Os Araweté “moram em aldeias por causa do milho” (VIVEIROS DE CASTRO, 1986: 264); “a aldeia é função do milho" (Op. Cit.: 286). Fundado nessas dinâmicas, torna-se plausível a piscadela latouriana proposta sobre as implicações de uma espécie de "sociologia vegetal" que funda as aldeias. Note-se que, em divergência com a percepção indígena, a ecologia amazônica frequentemente postula a centralidade da aldeia sobre a roça: “A produção de alimentos na Amazônia começa no quintal ao redor da maloca ou da aldeia, e se expande para pequenos roçados próximos intensamente manejados [...]. É importante ressaltar que a paisagem em torno da aldeia é um mosaico de roças, pequenas agroflorestas e parcelas de floresta manejadas ao longo da paisagem" (SHEPARD et al., 2020: 7).

19 Yofori wata me, um povo que os Banawá descrevem como habitante das florestas de terra-firme do rio Piranhas. 
Nem que o pessoal dos Jamamadi, que moram lá: não tinham fruta, não tinham jambo. Hoje em dia têm a casa deles cheia de jambo. A laranja por quê? Porque o missionário traz de Porto Velho. Vai querer fazer plantio e não vai querer sair do lugar das plantas dele, ele está morando. Moradia do índio é assim, começa assim. Através dele mesmo não tem. Para onde ele vai pega o babaçu, sabe que babaçu dentro da água dura muito. Onde chegam carregam babaçu e deixam num canto. Para onde ele vai ele deixa, para não carregar... - babaçu já pesa! Eles carregam e vão deixando. Pode passar um ano: se você deixar em terra a broca fura todinho e não presta, mas se você deixar dentro d'água pode passar um ano. Para onde ele chega lá no canto já tem aquele babaçu, só faz puxar panaco e ralar. A farinha deles é essa: o babaçu, o pão-de-índio, o louro-abacate. Ninguém encontra a aldeia. Mas hoje em dia têm essas malocas assim. Esses brabos, esses índios-de-rabo existem, mas eles não são mansos. Ninguém encontra a sua aldeia (Inácio, 2016, Foz do Aripuanã).

\section{A aldeia como política de exceção}

O diálogo com os Banawá me conduziu a suas ideias sobre os movimentos e transformações vividas ao longo desta itinerância através dos lugares e dos contrastes por eles estabelecidos até a formação das aldeias atuais. Não se trata de resolver um problema de ecologia histórica sobre as origens da agricultura banawá, mas de identificar as chaves da reflexão que eles desenvolvem sobre este processo, no movimento coletivo de parentes, caminhos, lugares. Retornemos aos vizinhos Suruwaha por um instante - eles que, nas últimas gerações, manifestam uma notória predileção pela caça junto com um "hiperdesenvolvimento" da horticultura. De fato, as roças suruwaha se destacam pela sua inédita amplitude, com uma escala em muito superior à que encontramos nos seus vizinhos Arawá. Alguns cultivares, como o abacaxi ou a pupunha, são plantados em tais proporções que eles não conseguem consumir tudo aquilo que plantam. Canaviais inteiros são cortados em competições rituais em que os homens carregam enormes feixes de cana em uma ostentação de fartura e força física. A região do igarapé Jukihi, onde os Suruwaha residiram nos últimos cem anos, apresentam um mosaico extensíssimo de capoeiras que testemunham o vigor da sua atividade hortícola. Por outro lado, a caça continua carregando um valor central na axiologia suruwaha: a biografia de um caçador é balizada pela quantidade de antas abatidas - um homem aponta orgulhosamente o número de linhas na cobertura da maloca que equivale ao montante de antas que caçou ao longo da vida, com uma memória minuciosa das circunstâncias e detalhes de cada captura. $\mathrm{O}$ karuji $i^{20}$ de um caçador forte se manifesta na destreza na caça, assim como na alta produtividade de seus roçados, capazes de produzir excedentes para momentos rituais.

20 Entre os Suruwaha, karuji designa tanto o "princípio vital" de uma pessoa, animal ou planta quanto o "carisma", a "liderança" que uma pessoa possui na sua rede de relações. 
Duas narrativas sobre a origem dos cultivares circulam na mitologia suruwaha. Em uma delas, as pessoas manifestam o seu "cansaço pela carne de caça" e pedem ao xamã Kawawari que chame os espíritos das plantas - ele replica objetando a dificuldade desse encontro. De todo modo, ele cede, e demanda a abertura de uma grande clareira na mata. Fica no centro da área derrubada e pede que as pessoas toquem fogo. As chamas alcançam Kawawari, que permanece em pé com sua filha no centro do roçado. Seus corpos queimam ${ }^{21}$ e o coração de Kawawari se eleva, pairando sobre as chamas. As futuras plantas, que são "as ex-coisas de Kawawari” (ahaba Kawawari iri zamakyba), estão debaixo da terra: quando a terra queima, as plantas começam a crescer e brotam no roçado. As plantas subiram girando em espiral até o alto do céu, e se transformaram em aves. Na terra surgiram a cana, os carás, o milho, o inhame, a mandioca, os cultivares aha, e Kawawari se transformou em uma ave grande e branca, parecida com o gavião.

Naquele tempo o povo fez uma caçada, as pessoas mataram antas e queixadas. O filho de Kawawari ouviu o som das buzinas huriatini. Ao chegar junto com as demais pessoas, avistaram uma grande clareira na mata. No centro da clareira, se erguia uma casa impressionante: ela era muito grande, bem construída, com redes muito bonitas no seu interior, com a mesma cor do urucum. Na casa moravam os espíritos das plantas, aha karuji, e Kawawari junto com eles. O filho de Kawawari tentou entrar nas roças, mas os espíritos do inhame o impediram, mostrando intenção de flechá-lo. O milho açoitava os corpos das pessoas que tentavam aproximar-se. Os espíritos das plantas impediam que as pessoas entrassem no roçado, até que, finalmente, foram aceitas. Conduziram o filho do xamã à casa que havia no meio dos cultivares. Kawawari assoprou tabaco no seu filho, assoprou repetidamente, até que o filho desfaleceu. Os espíritos vegetais lhe ofereceram garapa de cana e ficou restabelecido: ficou impressionado com a sua doçura. Seu pai lhe convidou para comer pupunha, banana, macaxeira, cará. Deu-lhe também mudas e sementes, que o filho levou e mostrou às pessoas. Quando encontrou com as pessoas de seu povo, elas pareceram sujas e feias aos seus olhos, em contraste com a beleza que tinha encontrado nos espíritos das plantas. Ofereceu as frutas, que todos acharam deliciosas. As pessoas prepararam cestos para carregar a carne das antas e queixadas abatidas na caçada. Comeram todos juntos na casa dos espíritos das plantas. Havia abundância de carne, macaxeira, frutas. As pessoas receberam sementes e mudas de todas as plantas do roçado, e as carregaram em cestos para plantar em outros lugares. Depois os espíritos das plantas foram embora.

Outras plantas tiveram origens diferentes: uma narrativa alternativa fala sobre o xamã Arigugu, que indicou que algumas plantas estavam no fundo das águas de um igarapé: havia algodão, flechas, urucum, abacaxi hahasa e banana katiahana. Inalou tabaco e disse ao seu neto: "Você quer ser xamã? Então mergulha lá e traz algodão, flechas, urucum, abacaxi hahasa e banana katiahana". O neto mergulhou, mas só conseguiu pegar areia com as mãos. As pessoas

21 O tema aparece também na mitologia apurinã: na versão dos Apurinã do Camicuã do mito de origem do roçado, as pessoas tentam queimar o corpo de Kanhunharu, dono do primeiro roçado, mas ele consegue safar-se colocando no seu lugar "o chefe de taboca", que morre (SCHIEL 2004: 230). Há outra versão semelhante entre os Apurinã de Itixi Mitari, registrada por Freitas (2017: 53). 
desistiram, foram embora; então Arigugu mergulhou no fundo do poço do igarapé e pegou o algodão, as flechas, o urucum, o abacaxi hahasa e a banana katiahana. Carregou as mudas no ombro e chegou a casa. Ele tinha visto no poço o algodão e demais plantas como se estivessem ao redor de uma casa. O poço era como uma casa, com as plantas em volta. Ao chegar a casa, deu as mudas e sementes às pessoas. Seu neto, admirado, disse: "Vovô, você estava certo! As plantas estavam debaixo d'água!".

Em ambas as narrativas, a roça e a casa aparecem estreitamente conectadas, como se a existência da primeira exigisse a presença concomitante da segunda. Esta correspondência entre os cultivares e a aldeia está no foco da reflexão banawá apresentada anteriormente, nas palavras de Inácio. Convencionalmente, algumas análises explicariam a trajetória banawá como uma "regressão agrícola": eles teriam abandonado a agricultura de uma época remota que a língua e a mitologia testemunham - o vocabulário das plantas presente na língua, análogo ao das outras línguas da família Arawá, seria uma das provas da ancestralidade de uma tradição agrícola perdida; além do mais, o ambiente do roçado, fadara, aparece constantemente em numerosos relatos míticos que descrevem os tempos antigos. Teriam optado, então, ao longo de várias gerações, por um modo de vida caçador-coletor, mais oportuno perante os efeitos das pressões externas, mais adequado diante da necessidade premente de mobilidade? Sob olhar da ecologia histórica, Balée (1994) - que interpreta como "regressão agrícola" processos análogos na Amazônia - avalia que a sobrevivência a partir da caça e da coleta somente seria viável em áreas altamente antropizadas, com profusão de plantas fornecedoras de alimentos e com um destacado precedente horticultor. De fato, o hinterland Purus-Piranhas onde os Banawá protagonizaram seus itinerários se destaca pela abundância de palmeiras (buriti, patauá, bacaba, babaçu...) e árvores com frutas que fazem parte da sua alimentação (pequiá, uxi, louro-abacate, castanheira...). Hoje a ecologia histórica e a arqueologia da Amazônia contestam a necessidade de uma passagem sequencial, progressiva, da caça/coleta à agricultura - como Neves declara, "não existe Neolítico ao sul do Equador" (2016) - e identificam os antigos habitantes das florestas amazônicas como "caçadores-coletores-domesticadores" 22 . Os paralelismos entre trekking e insegurança, por um lado, e cultivo permanente e estabilidade, por outro, são definitivamente questionáveis, e a diversidade de experiências coletivas entre os habitantes antigos e contemporâneos da Amazônia derruba qualquer hipótese determinante nesse sentido. De fato, o sistema de "agricultura de coivara" permite um elevado índice de mobilidade, e a opção pelo trekking caçador-coletor se justifica em diversos cenários pela conjugação ótima de liberdade e afluência que possibilita. Lévi-Strauss, em Do mel às cinzas ([1967] 2004: 66), já tinha reconhecido este "paradigma antineolítico" ameríndio, que anula o imperativo do progresso sequencial - da condição caçadora-coletora nômade à condição agricultora sedentária.

22 Conforme expos Charles Clement no curso sobre "Origem e domesticação das plantas cultivadas" (Instituto Nacional de Pesquisas da Amazônia, Manaus, 2015). Na mesma linha se situam as pesquisas de Smith e sua teoria dos nichos ecológicos $(2011 ; 2012)$. Como afirmam Levis et al., "esta perspectiva torna inadequada para o contexto amazônico a distinção típica entre caçadores-coletores versus grupos agrícolas (TERRELL et al., 2003; KENNEDY, 2012), já que a maioria dos antigos nativos amazônicos (muitas vezes caracterizados como caçadores-coletores) praticavam muitas atividades, incluindo o plantio de espécies arbóreas (FRIKEL, 1978)” (2018: 13-15). 
Não se trata de superar um vazio ou de ultrapassar um estado de precariedade tecnológica, mas de garantir a liberdade de escolha em uma recusa constante da estabilização. Isso quer dizer que a agrobiodiversidade das paisagens indígenas é, em realidade, um resultado da diversidade política dos coletivos.

Neste sentido, podemos observar algumas trajetórias expressivas, absolutamente diferenciadas. Assim, os Huaorani da Amazônia equatoriana, que persistem em um estilo de vida baseado na itinerância que prioriza a caça e a coleta silvestre, só recentemente intensificaram o cultivo de banana e mandioca para garantir o consumo cerimonial (RIVAL, 2002; 2015). A fase de aparente regressão agrícola dos Kanamari da Amazônia ocidental durante o seu envolvimento na economia da borracha, que deu origem a uma forma de vida com marcada mobilidade, é concebida por eles como um "movimento inútil" (COSTA, 2009): hoje eles retomaram, através do seu engajamento na economia regional (com forte presença de extrativistas), os mesmos cultivares que plantavam antes do contato - e persistem no seu estilo que combina práticas venatórias e horticultura. Por sua vez, na região das Guianas, os Waiwai identificam sua trajetória a partir da variabilidade e alternância entre movimentos de concentração em aldeias maiores que intensificam o plantio de roçados e movimentos de dispersão que reforçam o ideal de autonomia de pequenos grupos. Para eles não se trata de modelos excludentes - e consideram sempre o cultivo de mandioca como prática necessária para a produção de caiçumas, já que não há vitalidade ritual sem consumo de bebidas fermentadas (QUEIROZ, 2018). É conhecida também a experiência de fissão dos Parakanã do leste da Amazônia que, no século XX, produziram dois sistemas de organização contrastantes: os Parakanã ocidentais enfatizaram a vida itinerante em pequenos grupos autônomos, belicosos e dedicados à caça, enquanto que os Parakanã orientais geraram um sistema de metades exogâmicas em aldeias permanentes, praticantes de uma horticultura ausente entre os trekkers ocidentais (FAUSTO, 2001). Finalmente, vale a pena observar as transformações vividas pelos Awá-Guajá que, a diferença dos seus inimigos Ka'apor, teriam abandonado um padrão precedente de aldeia e agricultura, encontrando na itinerância da coleta e da caça uma opção vantajosa, e na floresta a sua habitação permanente (GARCIA, 2010; OTTO, 2018).

Esta multiplicidade de escolhas está presente também entre os coletivos arawá próximos aos Banawá. Como vimos, a pujança da horticultura suruwaha convive com a caça de antas, queixadas e macacos-barrigudos, que eles praticam como atividade preferencial. É verdade que as últimas gerações suruwaha têm estabelecido sua área residencial num território reduzido: dos anos 1930 até hoje, praticamente todas as casas têm sido construídas na microbacia do igarapé Jukihi, que constituiu uma região segura nos anos mais tensos do avanço extrativista - até a irrupção nos anos 1980 do protecionismo indigenista e missionário, hoje levado adiante pela Funai e os órgãos de assistência sanitária. Em contraste, os Hi Merimã contemporâneos vivem num isolamento proativo, evitando qualquer tipo de relação com outras populações indígenas ou ribeirinhas, e sem nenhum vestígio de atividade hortícola. São os únicos falantes de Arawá que não têm incorporado a mandioca à sua prática alimentar, e carecem de uma planta “indispensável para viver" entre os outros 


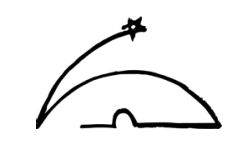

grupos - o tabaco. Porém, seu manejo da floresta evidencia uma intensa atividade arboricultora, desenvolve uma profusa rede de caminhos que conecta áreas distantes do interflúvio Purus-Juruá e dá sinais de um uso contínuo de pães-de-índio e tubérculos de terra-firme, como os do gênero Casimirella. Não há, portanto, estilos uniformes, apesar das semelhanças ecossistêmicas de grupos que habitam em uma mesma bacia hidrográfica.

Como afirmam Gow (2011) e Rival (2015), a escolha pela "perda da agricultura" - ou pela sua retomada, alternância ou incorporação - é uma escolha política. Não há progressão entre o trekking e o cultivo de mandioca, assim como não é impossível a simultaneidade entre ambos, em escalas diversas. Neste sentido, não me parece que o discurso aparentemente "evolucionista" de Inácio - sobre a suposta passagem de índios selvagens perambulantes a índios cultivadores aldeados - seja o eixo da questão. De fato, ele próprio demonstra um conhecimento refinado das práticas que seriam características dos "coletores" - Inácio, como qualquer pessoa adulta, as pratica e as conhece nos mínimos detalhes. Atualmente os Banawá, assentados em duas aldeias permanentes, mantêm simultaneamente diversos núcleos residenciais dispersos no seu território, que frequentam com assiduidade em todas as épocas do ano, em movimentos que não respondem apenas a calendários sazonais, mas a escolhas livres e desejos de autonomia individual. E ainda devem ser consideradas as contínuas excursões extrativistas (coleta de castanha, copaíba, pesca comercial de bagres) e as caçadas onde eles vivem em uma impermanência que, para eles, é compatível com a permanência da aldeia e do roçado. Mesmo na sua veemente negação da horticultura, os discursos banawá sobre a vida dos antigos deixam entrever que havia sempre diversos modos de manejo e cultivo de plantas nos quintais e nas proximidades dos acampamentos yobe bidi instalados nas encruzilhadas dos seus caminhos na floresta: espécies vegetais como o tabaco ou a pupunha faziam parte do cotidiano e talvez não eram plantadas em roçados, mas em quintais e hortas residenciais. Os Banawá não concebem a vida dos seus antecessores sem a presença dessas plantas "domesticadas" como parte da sua vida itinerante. Os relatos sobre Latawadi falam de plantios de flecheiras naquela região, assim como de milho e banana nos igarapés Waa e Mayofa. Declaram a origem roubada das plantas em um contexto de hostilidade e tensão como o mundo yara dos grandes rios. E, no movimento mais recente de pacificação dos yara, obtêm as manivas do seu patrão ao mesmo tempo em que se apropriam das espingardas, dos terçados e machados, das esporas para extrair látex de sorva, do sal, dos fósforos, das panelas metálicas e dos violões e vitrolas para as festas. Não é de surpreender que o mito banawá de origem das ferramentas e das mercadorias narre também a obtenção dos cultivares. A "inovação" das plantas cultivadas e da vida aldeã nos remete a um estado de incipiência permanente (NEVES, 2012), de alteração contínua. Em realidade, os Banawá das últimas gerações ensaiaram soluções instáveis entre o trekking e a aldeia, e mostram sempre a sua incapacidade de sedentarismo: apropriam-se das "plantas estabilizantes" dos roçados fadara, e ao mesmo tempo desfazem os movimentos de permanência. Vale a pena destacar que estas dinâmicas não remetem (somente) a uma escala de longa duração: se inserem nos limites da própria biografia dos adultos atuais. Bido, ao expor 
as lembranças da sua infância, conta que "naquele tempo [antes de estabelecer relações com o patrão Firmino] nós não tínhamos roçado, comíamos palmito de açaí e tucumã com a carne de anta, como os Hi Merimã. Comíamos uxi, pequiá, bacaba, ralávamos a polpa do coco de babaçu em uma lata e a torrávamos" (Bido, 2015, Paraíba). Não podemos negar que o aldeamento, a demarcação, a escola fazem parte da sua realidade contemporânea, mas são estruturas que não esgotam o desenvolvimento da vida coletiva.

Por isso as respectivas condições de "caçadores-coletores"23 e de "horticultores" não poderiam jamais ser disjuntivas na ontologia relacional dos Banawá ${ }^{24}$, a partir da qual viver socialmente não quer dizer viver em uma sociedade (INGOLD, 1999). Em um sentido correspondente, nomadismo e sedentarismo são categorias insuficientes para definir a vida banawá passada ou presente: "Antes que espacial, essa territorialidade é topológica: o espaço que ela exige é aquele que permite organizar as relações de modo que proximidades e distâncias sejam eficientes" (CALAVIA, 2015: 273). O que nós denominamos território, mais do que uma geografia, é um memorando de pessoas-lugares que projeta os dilemas do parentesco e da diferença, que se constrói a partir da multiplicidade de subjetividades que interagem. Neste sentido, a vida com as sementes de taioba nos tempos do igarapé Waa, os perigos do timbó no Mayofa, as panelas de yamabia na Maloca Grande e as novas roças de mandioca janoacá na aldeia Paraíba ${ }^{25}$ definem maneiras de convivência multiversal que as pessoas vão desenvolvendo ao longo do tempo, no trânsito através de lugares que atualizam as possibilidades do parentesco. A aldeia se torna estado excepcional em uma vida inquieta de deslocamentos contínuos, marcada por uma cosmopolítica humano-vegetal de entrelaçamentos impermanentes.

\section{Referências}

ALMEIDA, Mauro. As colocações: forma social, sistema tecnológico, unidade de recursos naturais. Mediações. Revista de Ciências Sociais, v. 17, n. 1, 2012. Disponível em: http://dx.doi.org/10.5433/2176-6665.2012v17n1p121. Acesso em 22 mar. 2017.

ALTMANN, Lori. Madija, um povo entre a floresta e o rio. Trilhas da produção simbólica Kulina (Mestrado em

23 Em relação aos Banawá, deveríamos acrescentar sempre a esta designação a condição de "pescadores de timbó" que os caracteriza. O uso de venenos de pesca nos igarapés de terra-firme é uma prática antiga e contemporânea que os Banawá desenvolvem destacadamente.

24 Veja-se a crítica oportuna que Viveiros de Castro faz a Bird-David (1999), quando a autora substancializa atributos dos caçadores-coletores que encontramos também nos horticultores, como a partilha com as pessoas próximas, considerada por ela essência da vida social dos primeiros.

25 Faço referência a diversos episódios da vida banawá (APARICIO, 2019): as diminutas sementes de taioba makafira foram o veículo que os antigos xamãs Afifata, Nokinimeri e Yowaki utilizaram para resgatar Maana, mulher raptada pelos espíritos subterrâneos; o consumo da dioscoreácea yamabia é apontado como uma das referências culinárias mais destacadas na vida em Tabora Made; e a mandioca janoacá, obtida dos ribeirinhos, caracteriza uma das preferências contemporâneas dos Banawá para a elaboração da farinha de mandioca. 


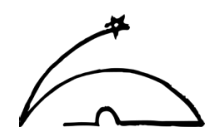

Ciências da Religião) - Instituto Metodista de Ensino Superior, São Bernardo do Campo, 1995.

AMORIM, Genoveva. O ritual kulina do Ajie: Movimentando os coletivos madija. In: Mendes dos Santos, Gilton \& Aparicio, Miguel (orgs.). Redes Arawa. Ensaios de etnologia do Médio Purus. Manaus: Edua, 2016, p. 111-132.

ANTUNES, André. Época da fantasia. PISEAGRAMA, n. 10, p. 20-25. Belo Horizonte, 2017.

APARICIO, Miguel. Presas del Veneno. Cosmopolitica y Transformaciones Suruwaha. Quito: Editorial Universitaria Abya Yala, 2015.

APARICIO, Miguel. A relação banawá. Socialidade e transformação nos Arawá do Purus (Doutorado em Antropologia Social) - PPGAS, Museu Nacional, Rio de Janeiro, 2019.

BALÉE, William. Footprints of the forest: Ka'apor ethnobotany. The historical ecology of plant utilization by an Amazonian people. New York: Columbia University Press, 1994.

BELAUNDE, Luisa E. A força dos pensamentos, o fedor do sangue. Hematologia e gênero na Amazônia. Revista de Antropologia, v. 49, n. 1, p. 205-243, 2006. Disponível em: https://doi.org/10.1590/S0034-77012006000100007. Acesso em 10 ago. 2018.

BIRD-DAVID, Nurit; VIVEIROS DE CASTRO, Eduardo; HORNBORG, Alf; INGOLD, Tim; MORRIS, Brian; PÁLSSON, Gisli; RIVAL, Laura M.; SANDSTROM, Alan R. “Animism” Revisited: Personhood, Environment, and Relational Epistemology [and Comments and Reply]. Current Anthropology, v. 40, 1999. Disponível em: http:// www.jstor.org/stable/10.1086/200061. Acesso em 26 jun. 2018.

CABRAL DE OLIVEIRA, Joana. Mundo de roças e florestas. Boletim do Museu Paraense Emílio Goeldi. Ciências Humanas, v. 11, n. 1, p. 115-131, 2016. Disponível em: http://dx.doi.org/10.1590/1981.81222016000100007. Acesso em 2 jun. 2017.

CALÁVIA, Oscar. O território, visto por outros olhos. Revista de Antropologia, v. 58, n. 1, p. 258-284, 2015. Disponível em: https://doi.org/10.11606/2179-0892.ra.2015.102108. Acesso em 15 abr. 2016.

CHIMANOVITCH, Mário. O índio pacifica o branco. O Estado de São Paulo, edição de 15 jan. 1974.

CLASTRES, Pierre. Crônica dos Índios Guayaki. O que sabem os Aché, caçadores nômades do Paraguai. Rio de Janeiro: Editora 34, [1972] 1995.

COELHO DE SOUZA, Marcela (org.). T/terras indígenas e territórios conceituais: incursões etnográficas e contro- 
vérsias públicas. EntreTerras, vol. 1, n. 1, p. 1-60, 2017.

COSTA, Luiz A. Worthless Movement: Agricultural Regression and Mobility. Tipiti: Journal of the Society for the Anthropology of Lowland South America, v. 7, n. 2, p. 151-180, 2009. Disponível em: https://digitalcommons.trinity. edu/tipiti/vol7/iss2/2. Acesso em 8 jun. 2018.

DAL POZ, João. No País dos Cinta Larga. Uma etnografia do ritual (Mestrado em Antropologia Social), PPGAS, Universidade de São Paulo, São Paulo, 1991.

FAUSTO, Carlos. Inimigos fiéis. História, guerra e xamanismo na Amazônia. São Paulo: Edusp, 2001.

FREITAS, Admilton. A roça, a colheita e a festa: uma etnografia dos rocados apurinã da aldeia Terra Nova (Mestrado em Antropologia Social), PPGAS, Universidade Federal do Amazonas, Manaus, 2017.

GARCIA, Uirá F. Karawara: a caça e o mundo dos Awá-Guajá. Tese (Doutorado em Antropologia Social), PPGAS, Universidade de São Paulo, São Paulo, 2010.

GONÇALVES, Marco Antônio. O mundo inacabado. Ação e criação em uma cosmologia amazônica: Etnografia pirahã. Rio de Janeiro: Editora da UFRJ, 2001.

GOW, Peter. Canção Purús. Nacionalização e tribalização no sudoeste da Amazônia. Revista de Antropologia, v. 49, n. 1, p. 431-464, 2006. Disponível em: https://doi.org/10.1590/S0034-77012006000100013. Acesso em 9 nov. 2018.

GOW, Peter. "Me deixa em paz!" Um relato etnográfico preliminar sobre o isolamento voluntário dos Mashco. Revista de Antropologia, v. 54, n. 1, p. 11-46, 2011. Disponível em: https://doi.org/10.11606/2179-0892.ra.2011.38582. Acesso em 21 set. 2017.

INGOLD, Tim. On the social relations of the hunter-gatherer band. In: Lee, Richard B.; Daly, Richard (eds.). The Cambridge Encyclopedia of Hunters and Gatherers, Cambridge: Cambridge University Press, p. 399-410, 1999.

KELLY, José A. Notas para uma teoria do "virar branco". Mana: Estudos de Antropologia Social, v. 11, n. 1, p. 201234, 2005. Disponível em: https://doi.org/10.1590/S0104-93132005000100007. Acesso em 30 jun. 2018.

LAGROU, Els. Rir do poder e o poder do riso nas narrativas e performances kaxinawa. Revista de Antropologia, v. 49, n. 1, p. 55-90, 2006. Disponível em: https://doi.org/10.1590/S0034-77012006000100003. Acesso em 7 abr. 2018.

LÉVI-STRAUSS, Claude. Guerra e comércio entre os índios da América do Sul. In: SCHADEN, Egon (org.). Leituras de etnologia brasileira. São Paulo: Companhia Editora Nacional, 1976. 


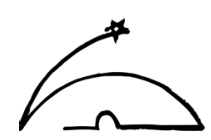

LÉVI-STRAUSS, Claude. Mitológicas. 2. Do mel às cinzas. São Paulo: Cosac Naify. [1967] 2004.

LEVIS, Carolina; FLORES, B. M.; MOREIRA, P. A.; LUIZE, B. G.; ALVES, R. P.; FRANCO-MORAES, J.; ... CLEMENT, Ch. R. How people domesticated Amazonian forests. Frontiers in Ecology and Evolution, n. 5, p. 171s., 2018. Disponível em: https://www.frontiersin.org/articles/10.3389/fevo.2017.00171/full. Acesso em 22 jul. 2018.

NEVES, Eduardo Góes. A incipiência permanente. Conferência proferida no Seminário "Antropologia e Arqueologia da Amazônia". Belo Horizonte: UFMG/FAFICH, 2012.

NEVES, Eduardo Góes. Não existe Neolítico ao Sul do Equador: as primeiras cerâmicas amazônicas e sua falta de relação com a agricultura. In: Barreto, Cristiana; Lima, Helena Pinto; Betancourt, Carla Jaimes (orgs.). Cerâmicas arqueológicas da Amazônia: rumo a uma nova sintese. Belém: IPHAN - Museu Paraense Emílio Goeldi, 2016.

OTTO, Renata. A besta árida: uma perspectiva "antineolítica" entre os Awá-Guajá, Tupi no Maranhão. Teoria e Sociedade, n. 24/2, p. 131-154, 2018. Disponível em: http://www.teoriaesociedade.fafich.ufmg.br/index.php/rts/ article/view/290. Acesso em 2 fev. 2018.

QUEIROZ, Rubens C. A perspectiva antineolítica abaixo do Equador: Relato de um caso etnográfico Carib nas Guianas. Teoria e Sociedade, n. 24/2, p. 115-129., 2018. Disponível em: http://teoriaesociedade.fafich.ufmg.br/index. php/rts/article/view/289. Acesso em 5 fev. 2018.

RIVAL, Laura M. Trekking through History. The Huaorani of Amazonian Ecuador. New York: Columbia University Press, 2002.

RIVAL, Laura M. Transformaciones Huaorani. Frontera, cultura y tensión. Quito: Ediciones Abya Yala, 2015.

RODGERS, David. A soma anômala: a questão do suplemento no xamanismo e menstruação ikpeng. Mana: Estudos de Antropologia Social, v. 8, n. 2, p. 91-125, 2002. Disponível em: https://doi.org/10.1590/S0104-93132002000200004. Acesso em 31 mai. 2018.

SCHIEL, Juliana. Tronco velho. Histórias apurinã. Tese (Doutorado em Antropologia), PPGAS, Universidade Estadual de Campinas, Campinas, 2004.

SCHRÖDER, Peter - MAIZZA, Fabiana. Verbete "Jarawara”. In: Instituto Socioambiental, Povos Indígenas do Brasil. Disponível em: https://pib.socioambiental.org/pt/Povo:Jarawara. Acesso em 12 mar. 2018.

SHEPARD, Glenn H.; NEVES, Eduardo G.; CLEMENT, Charles R.; LIMA, Helena; MORAES, Claide; MENDES DOS SANTOS, Gilton. Ancient and Traditional Agriculture in South America: Tropical Lowlands. In: Oxford Rese- 
arch Encyclopedia of Environmental Science. Oxford University Press, 2020. Disponível em: https://doi.org/10.1093/ acrefore/9780199389414.013.597 Acesso em 29 mar. 2020.

SHIRATORI, Karen. O olhar envenenado: da metafisica vegetal Jamamadi. Tese (Doutorado em Antropologia Social), PPGAS, Museu Nacional, Rio de Janeiro, 2018.

SMITH, Bruce D. General patterns of niche construction and the management of 'wild' plant and animal resources by small-scale pre-industrial societies. Philosophical Transactions of The Royal Society-Biological Sciences, n. 366, 2011. Disponível em: https://www.ncbi.nlm.nih.gov/pmc/articles/PMC3048989/. Acesso em 28 fev. 2018.

SMITH, Bruce D. A Cultural Niche Construction Theory of Initial Domestication. Biological Theory, v. 6, n. 3, p. 260-271, 2012. Disponível em: https://doi.org/10.1007/s13752-012-0028-4. Acesso em 6 fev. 2018.

VIVEIROS DE CASTRO, Eduardo. Araweté: os deuses canibais. Rio de Janeiro: Jorge Zahar/ANPOCS, 1986.

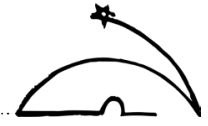

